\title{
Okul Öncesi Aday Öğretmenlerin Öğrenme Stillerinin Matematiksel Algoritmaya Dayalı Olarak Modellenmesi
}

\begin{tabular}{lccc}
\hline MAKALE TÜRÜ & Başvuru Tarihi & Kabul Tarihi & Erken Görünüm Tarihi \\
Araştırma Makalesi & 16.11 .2017 & 14.03 .2018 & 15.03 .2018 \\
\hline
\end{tabular}

Gökhan Güneş

Hakkari Üniversitesi

Öz

$\mathrm{Bu}$ araştırmanın amacı, okul öncesi öğretmen adaylarının öğrenme stillerinin, matematiksel bir algoritma yöntemi kullanılarak modellenmesidir. Çalışma 2015-2016 akademik yılında Ankara ilinde bulunan bir devlet üniversitesinin okul öncesi eğitimi anabilim dalında öğrenim gören 159 lisans öğrencisi ile yürütülmüştür. Araştırmada veri toplama aracı olarak Felder ve Soloman (1994)'ın Öğrenme Stilleri Envanteri kullanılmıştır. Araştırma sonuçlarına göre öğretmen adaylarının sağ yarıküre kontrolündeki aktif, algısal ve görsel öğrenme stillerini ağırlıklı olarak tercih ettikleri saptanırken; sol yarıküre kontrolündeki sıralı (analitik) öğrenme stilini de bütüncül (global) öğrenme stiline oranla daha fazla kullandıkları ortaya çıkmıştır. Bununla beraber araştırmada yer alan öğretmen adaylarının öğrenme stillerinde yaklaşık olarak \% 11 oranında sağ yarıküre temelli stillere kaydıkları belirlenmiştir. Bununla beraber geliştirilen modelleme sonucunda sapmanın fazla olduğu öğrenme stili güçlerinin de \% 12 yansıtıcı/aktif ve \% 16 işitsel/görsel alt boyutlarında kayba uğradığı hesaplanmıştır.

Anahtar sözcükler: Öğrenme stilleri, matematiksel model, okul öncesi öğretmen adayları

\footnotetext{
${ }^{1}$ Sorumlu Yazar: Yrd. Doç. Dr., Eğitim Fakültesi, İlköğretim Bölümü, Okul Öncesi Eğitim A.B.D., Eposta: gokhangunes@hakkari.edu.tr, https://orcid.org/0000-0002-8923-3315
} 
İnsan psikolojisi üzerine yapılan çalışmalar, bireysel farklılıkların, bireylerin öğrenme, anlama ve algılama gibi yeterlilikleri ile geliştirdikleri davranışların temelinde önemli bir etkiye sahip olduğuna işaret etmektedir. Psikoloji çalışmalarının 19. yüzyıl sonlarına doğru bireysel farklılıklar üzerinde şekillendiği görülmektedir (Sharp, 1899). Bireysel farklılıklar her insanda diğer insanlardan farklı olarak davranış ya da fiziksel görünümde algılanan eşsiz farklılıklar olarak tanımlanabilir (Akpan, Essien ve Okure, 2013). Bireylerin sahip oldukları farklılıklar, öğrenme süreçlerinin de farklılaşmasına başka bir deyişle öğrenmenin de kişisel bağlamda bireysel bir süreç olmasına işaret etmektedir. Bu süreç bireylerin öğrenme eğilimlerinin ya da tercihlerinin de farklı özellikler gösterdiği öğrenme stilleri ile açıklanabilir. Ekici (2002) bu noktada öğrenme stillerini bireysel farklılıkları ifade eden en önemli kavramlardan biri olarak görmektedir.

Dunn, Griggs, Olson ve Beasley (1995) öğrenme stillerini, her bir öğrencinin yeni ve zor bilgiyi öğrenmeye hazırlanırken, öğrenirken ve hatırlarken farklı ve kendilerine özgü yollar kullanması olarak belirtmektedir. Bununla beraber öğrenme stilleri üzerinde çevresel, sosyal, duygusal, psikolojik ve fiziksel etmenlerin önemi vurgulanmıştır. Keefe (1979) öğrenme stillerini, öğrenenlerin algıları, etkileşimleri ve öğrenme ortamlarında verdikleri tepkileri gösteren, bilişsel ve psikolojik davranışlar olarak kabul etmektedir. Kolb (1984) ise öğrenme stili modelinde, öğrenmeyi, bilginin üretiminden deneyime dönüştürülme süreci olarak tanımlamaktadır. Farklı bir yaklaşım olarak Felder ve Brent (2005) ise öğrenme stillerini kısaca bilginin alınma ve işlenme süreci olarak değerlendirmektedir. Gregorc (1979), bireyleri harekete geçiren bir iç kuvvetten söz ederek bu kuvvetin öğrenme stillerini belirlediğini açıklamıştır. Bunun yanı sıra öğrenme stillerinin, bilginin algılanmasında oynadığı role dikkat çekerek öğrenme sürecindeki etkisini vurgulamaktadir.

Öğrenme stillerinin akademik başarı ile ilişkisi yapılan birçok araştırma ile ortaya konulmuştur. Felder ve Soloman (1994), öğrencilerin akademik başarılarının öğrenme stilleri ile aldıkları derslerin anlatım teknikleri arasındaki uyumla ilişkili olduğunu belirtmektedir. $\mathrm{Bu}$ bağlamda, akademik başarısızlıkların sadece öğrencilerin konuları anlayamaması ya da öğrencilerin yetersizliklerinden kaynaklanmadığını, akademik başarı için öğretme tekniklerinin de öğrencilerin öğrenme stillerine uygun olması gerektiğini savunmaktadırlar. Benzer şekilde Dilci ve Babacan (2011) lisans düzeyindeki eğitim programlarında bireysel farklılıklara ve farklı zeka alanlarına yer verilmemesinin öğrencilerin üst düzeyde düşünmelerine engel olduğunu ve öğrencilerin akademik başarılarını olumsuz etkilediğini belirtmektedir.

Pehlivan (2010) geleneksel bilgi aktarma yoluyla bilgi çağı insanının yetiştirilemeyeceğini belirtmektedir. Buradan hareketle bilgi çağı insanını yetiştirecek olan öğretmenlerin de geleneksel bilgi kuramları ile yetiştirilmeyeceği anlaşılmaktadır. Kişilerin öğrendikleri şekilde öğrettikleri düşüncesinden hareketle aday öğretmenlerin ilerde nasıl bir öğretim yaklaşımına sahip olacakları da 
kestirilebilir. Dunn ve diğ. (1995) öğretmenlerin öğrenme stillerinin, öğrencilerin öğrenme stillerini çoğu zaman şekillendirdiğini, okul öncesi öğretmenleri ve dönem çocukları ile yaptıkları çalışmayla ortaya koymuşlardır. Okul öncesi dönem öğretmenlerinin, kinestetik, görsel ve algılamaya dayalı öğrenme yaklaşımları oldukları saptanmıștır ve bu öğrenme yaklaşımlarını, çocuklara uyguladıkları etkinliklerde sıkça kullandıkları rapor edilmiştir. Felder ve Soloman (1994)'ın lisans öğrencileri ile yaptıkları çalışmalarda ise lisans öğrencilerinin aktif ve görsel öğrenme stillerine sahip olmalarına rağmen ders içeriklerinin soyut ve işitsel öğrenmelere dayalı olması, öğrenci başarılarını olumsuz etkileyen etmenler olarak gösterilmiştir.

Öğrenme üzerine yapılan çalışmalar sonucunda, öğrenme stilleri, düşünme, anlama ve problem çözme gibi zihinsel becerilerin tümünün beynin işlevi ve gelişimsel süreci ile şekillendiği ortaya konulmuştur (Giedd, Snell, Lange, Rajapakse, Casey, Kozuch, Vaituzis, Vauss, Hamburger, Kaysen ve Rapoport, 1996; Reiss, Abrams, Singer, Ross ve Denckla, 1996). Erken çocukluk döneminde bu gelişimsel sürecin davranışlarda, duygularda, hormonlarda ve bilişsel işlemlerde önemli bir rol oynadığ öğrenme stilleri ile beynin bilgiyi alma, işleme-yapılandırma ve konumlandırma süreçleri arasında ilişki olduğu görülmektedir. $\mathrm{Bu}$ ilişkinin sadece çocukluk döneminde değil, yaşamın her dönemine ait olduğu söylenebilir. Öğrenme stilleri ile beyin yarı küreleri arasındaki ilişkinin incelendiği araştırmalara göre sol yarıküreyi yoğun kullanan bireylerde analitik ve tümevarım etkinlikleri ile hedefe küçük adımlarla ve parça parça ilerlendiği saptanmıştır. Öte yandan sağ yarıüreyi kullanan bireylerde genel ve tümdengelim etkinlikleri ile hedefe geniş bir kavramdan yola çıkarak anlamlandırma ve sonrasında parçalara ulaşmanın söz konusu olduğu belirlenmiştir (Dunn, Beaudry ve Klavas, 1989; Iaccino, 2014; Zhang, 2011).

Son dönemde yapılan çalıșmalarda beyin yarıküreleri ile öğrenme stilleri arasındaki güçlü ilişkiler derinlemesine incelenerek sol beyin yarıküreyi yoğun kullanan bireylerin görsel, işitsel ve her iki öğrenme ortamında da daha iyi öğrendikleri, sağ yarıüreyi kullanan bireylerin ise sadece görsel öğrenme ortamlarında daha iyi öğrenebildikleri belirlenmiştir (Zhang, 2011). Sol yarıkürede mantıksal ve sıralı düşünme, dil bilgisi, kelime ve matematik denklemleri gibi işlemlerin, sağ yarıkürede ise anlık, bütünsel, imgesel düşünme ve ortamları/şekilleri algılama işlemlerinin kontrol edildiği ve sol yarıürede güçlü şekilde yürütülen işlevlerinin sağ yarıkürede zayıf olarak yürütüldüğü vurgulanmaktadır (Iaccino, 2014). Herrmann (1990) ise sol üst ve alt çeyrek ile sağ üst ve alt çeyrek olmak üzere beyni dört çeyrekli bütünsel bir modelle açıklamaktadır. Modelde yer alan sol üst çeyrek rasyonel, matematiksel, analiz işlemler ve gramer gibi konulardan, sol alt çeyrek ayrıntılar, metodik düşünme ve motor becerilerinden sorumludur. Öte yandan sağ üst çeyrek kinestetik, resim, şiir ve bütünü kavrama becerilerinden, sağ alt çeyrek ise müzik, iletişim, kodlama ve anadili kullanma gibi becerilerden sorumludur. 


\section{Modellemenin Tanımı ve Özellikleri}

Alanyazında öğrenme stillerine ilişkin farklı tanımlamalar ve tanımlamalara bağlı olarak geliştirilen çeşitli modeller olduğu görülmektedir (Dunn ve Dunn, 1999; Felder ve Soloman, 1994; Fleming, 2001; Gregorc, 1979; Kolb, 1984). Geliştirilen modelleme örneklerinde bireylerin/ çocukların öğrenme tercihleri ve öğrenme eğilimlerinin bilişsel ve mekansal değerlerle ölçümlendiği görülmektedir. Gilbert (2004) ile Harrison ve Treagust (2000) modellemeyi, bilinmeyen bir hedefi açık ve anlaşılır duruma getirmek için yapılan işlemler bütünü olarak tanımlanmaktadır. Buradan hareketle soyut aksiyomlarla belirtilen öğrenme stillerini, modelleme yöntemi ile incelenmesi, aday öğretmenlerin öğrenmelerine ilişkin daha detaylı somut ve ölçülebilir yaklaşımlar geliştirilmesine olanak sağlayabilir. Bu bağlamda öğrenme stilleri üzerine zaman içerisinde geliştirilen modelleme örneklerinden (Dunn ve Dunn, 1992; Felder ve Soloman, 1994; Gregorc, 1979; Kolb, 1984) farklı olarak, Felder ve Soloman (1994)'ın geliştirdiği Öğrenme Stilleri Envanteri (ÖSE) sonuçları üzerinden aday öğretmenlerin öğrenme stillerinin matematiksel modellemesine ulaşılmaya çalışılacaktır.

\section{Öğrenme Stili Modelinin Kuramsal Temelleri}

Araştırmada geliştirilen model, iki temel varsayıma dayanmaktadır. İlk varsayım, beyin sağ ve sol yarıürenin öğrenme stilleri üzerindeki işlevi ve ikinci varsayım öğrenme stillerinin zihinde oluşturdukları öğrenme stili alanları ve öğrenme stili alanlarının ortak etkisinde oluşan öğrenme stili gücüdür.

\section{Beyin Sağ ve Sol Yarıürenin Öğrenme Stilleri Üzerindeki Fonksiyonu}

Modelin ilk varsayımı, beyin yarıürelerinin öğrenme tercihlerinde etkili olduğu ya da diğer bir ifade ile öğrenmenin beynin sağ ya da sol yarıürenin kontrolünde gerçekleşmesidir. $\mathrm{Bu}$ varsayım daha önce yapılan araştırmaların sonuçlarından hareketle kabul edilmiştir (Giedd ve diğerleri, 1996; Lebel ve Beaulieu, 2011; Dunn ve Dunn, 1996; Iaccino, 2014; Zhang, 2011; Herrmann, 1990). Sonuç olarak ilgili alanyazında farklılıklar olsa da genel olarak araştırmacı tarafından sol beyin yarıküre fonksiyonları, analitik, mantıksal, kurallı, gerçekçi, sayısal/niceliksel, sıralı, organize, planlı, içe kapanık, detaycı, soyut, konuşma, işitsel, düşünerek öğrenme; sağ beyin yarıküre fonksiyonları ise imgesel, bütünsel, birleştirici, sentezleyici, sosyal zeka, dişa dönük, kinestetik, duygusal, somut, görsel ve yaparak öğrenme olarak gruplanmıştır. Geliştirilen modelin formülasyon çalışmalarında, De Bello (1990), Healy (2004) ve Felder (1996)'in yaklaşımları referans olarak alınmıştır. Bireylerin beyinlerinin tümü ile öğrendikleri (Healy, 2004) ve etkili bir öğrenen olmanın, iki karşıt kutuptaki becerileri göstermeyi gerektirdiği kabul edilmiştir (De Bello, 1990). Bu bağlamda, bireylerin en etkili ve en yüksek öğrenme kapasitelerine sağ ve sol yarıküreye dengeli dağılan öğrenme stili tercihleri ile ulaşabilecekleri savunulabilir (Felder, 1996). 


\section{Öğrenme Stillerinin Zihinde Oluşturdukları Öğrenme Stili Alanları ve Öğrenme Stili Alanlarının Ortak Etkisinde Gelişen Öğrenme Stili Gücü}

Öğrenme ortamları ya da ölçme ve değerlendirme koşulları her zaman bireylerin öğrenme eğilimlerine uygun olarak düzenlenmemiş olabilir. Bu nedenle etkili bir öğrenenin tüm öğrenme stillerini dengeli kullanabilmesi beklenmektedir. Öğrenme stillerinin (ÖS) yarıkürelerde öğrenme stili alanlarını (Sös) oluşturduğu kabul edilerek bireylerin öğrenme tercihlerinin zihinde nasıl bir alan kapladığı ve bu alanın hangi yarıkürede yoğunlaştığı hakkında yorum yapılabilir. Bunun yanı sıra her iki yarıkürede oluşan öğrenme stili alanlarının ortak etkisinde gelişen "öğrenme stili gücü $\left(\mathrm{G}_{\mathrm{O} s}\right)$ ", öğrenmeye-akademik başarıya ya da bilişsel gelişime ilişkin ipuçları verebilir.

Öğrenme stili alanlarının hesaplanmasına, öğrenme stili tercih frekanslarının (fös) bulunmasıyla başlanır. Bulunan frekanslar sol ve sağ yarıürede, öğrenme stili noktaları (pös) olarak tanımlanmaktadır. Sol yarıkürede (LH) yer alan pös'ler için $\mathrm{p}_{\mathrm{LH}}$, sağ yarıkürede $(\mathrm{RH})$ yer alan pös'ler içinde $\mathrm{p}_{\mathrm{RH}}$ ifadeleri kullanılmaktadır. $\mathrm{Bu}$ noktalar frekanslara bağlı olduğu için 0-1 arasında değişen değerler alacaktır. $\mathrm{p}_{\mathrm{LH}}$ ile $\mathrm{p}_{\mathrm{RH}}$ arasından geçen doğru, geliştirilen modelde öğrenme stili doğrusu $\left(\mathrm{d}_{\mathrm{ÖS}}\right)$ olarak adlandırılmaktadır. Analitik düzlemde yer alan apsis ekseninde $(x)$ sol-sağ yarıküre doğrusu olarak, sol yarıürede .50 br ve sağ yarıürede de .50 br olmak üzere toplam 1.00 br uzunlukta olduğu kabul edilmiştir. Apsis eksenini $90^{\circ}$ açı ile eșit iki parçaya bölerek kesen ordinat ekseni $(y)$ ise öğrenme stili frekans dağ 1 lım doğrusudur ve 1.00 br uzunluktadır. $y$ ekseninin saat yönünün tersinde kalan bölgesi LH, saat yönünde olan bölgesi ise RH'yi temsil etmektedir. Buna göre LH'de oluşan $S_{\text {Ös }}$ ler için $S_{L H}$, RH'de oluşan $S_{\text {ös }}$ 'ler içinde $S_{R H}$ ifadeleri kullanılmaktadır. $f_{L H}$ ve $f_{R H}$ 'nin skaler çarpımı sonucu elde edilen ÖS gücü ise $G_{O ̈ S}$ olarak belirtilmektedir. Algoritmada belirtilen formüllerin kullanımı ve elde edilen modelin çizimine ilişkin örnek Şekil 1'de, daha ayrıntılı anlatımlar ve gösterimler, bulgular bölümünde araştırmadan elde edilen sonuçlara ilişkin olarak verilmiştir.

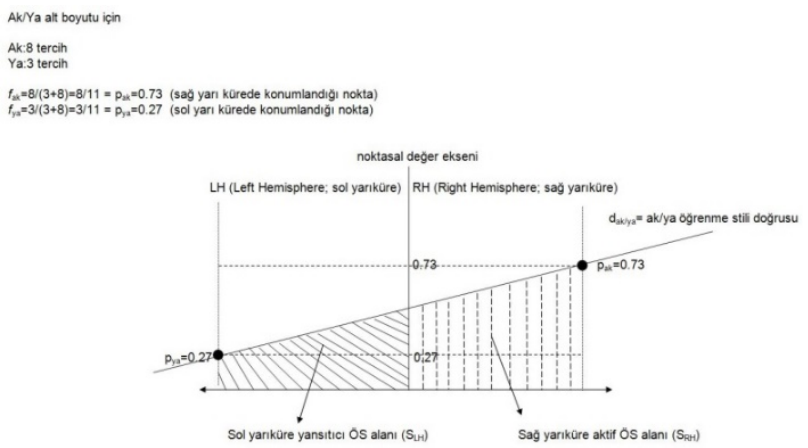

Şekil 1. ÖS modeline ilişkin noktasal değerler, doğruların çizimi ve ÖS alanlarının gösterimi 
Modelde ulaşılan her ÖS modelinin değerlendirilmesinde, en yüksek öğrenme stili (maxÖS) modeli referans alınmıştır. maxÖS her iki ÖS'nin de dengeli dağılımı sonucu oluştuğu kabul edilen teorik bir modeldir. maxÖS modelinde; $\mathrm{p}_{\mathrm{LH}}=\mathrm{p}_{\mathrm{RH}}=.50$ 'dir, buna göre $\mathrm{d}_{\mathrm{ÖS}}=y=.50$ olarak çizilir. $\mathrm{d}_{\mathrm{O} S}$ altında kalan $\mathrm{S}_{\mathrm{LH}}=\mathrm{S}_{\mathrm{RH}}=25 \times 10^{-2} \mathrm{~S}, \mathrm{~S}_{\mathrm{O} S}$ de $50 \times 10^{-2} \mathrm{~S}$ ve modelin $\mathrm{G}_{\mathrm{ÖS}}$ ise $25 \times 10^{-2} \mathrm{G}$ olarak bulunur. Elde edilen modellerdeki $S_{O ̈ S}$ ve $G_{O ̈ S}$ değerlendirilmeleri maxÖS'e göre yapılmaktadır. Ulaşılan modellerde, dös'lerde meydana gelen sapmalar, SÖS'lerin değişimine (azalış-artış) ve fös'lerin değerlerine bağlı olarak hesaplanan $\mathrm{G}_{\text {Ös }}$ 'lerin de maxÖS'e göre kaybına işaret etmektedir. döslerde meydana gelen sapmalar, maxÖS modelindeki $y=.50$ doğrusu ile yaptığı açı olarak bulunur ve bu açının artması sapmanın büyümesi, alanların değişim miktarlarının artması ve dolayısıyla $\mathrm{G}_{\text {ös }}$ lerin de azalması olarak yorumlanabilir. $\mathrm{S}_{\text {ÖS }}$ ve $\mathrm{G}_{\text {ÖS }}$ ' lerin maxÖS'e oranı, alanlarda değişimin, güçte ise kaybın yüzdelik oranını verecektir.

Modellemenin tanımları ve algoritmasına ilişkin formülleri Tablo 1'de sunulmuştur.

Tablo 1.

Ögrrenme Stili Modelinde Yer Alan Tanımlar ve Formülleri

\section{Tanımlar ve Formüller}

$f_{y a}, f_{s e}, f_{i s} v e f_{s v}$, sırasılyla sol yarıürede (LH) yer alan Yansitıcı (ya), Sezgisel (se), İşitsel (iş) ve Sıralı (sı) alt boyutlarındaki öğrenme stili (ÖS) frekanslarıdır ve genel gösterimi $f_{l}$ şeklindedir. Benzer şekilde $f_{a k}, f_{a l}, f_{g o ̈} v e f_{b u ̈}$ sirasiyla sağ yarıürede (RH) yer alan Aktif (ak), Algısal (al), Görsel (gö) ve Bütünsel (bü) alt boyutlarındaki ÖS frekanslarıdır ve genel gösterimi $f_{r}$ şeklindedir. $f_{1}$ ve $f_{\mathrm{r}}$ LH ve RH'deki ÖS noktalarını $\mathrm{p}_{l}$ ve $\mathrm{p}_{r}$ ifade eder.

$p_{l} \rightarrow f_{l}=\frac{f_{l}}{f_{l}+f_{r}} ; p_{r} \rightarrow f_{r}=\frac{f_{r}}{f_{l}+f_{r}} \quad$ ÖS modelinde her zaman:

$\left|f_{l}\right|+\left|f_{r}\right|=1.00$

$\mathrm{p}_{l}$ ve $\mathrm{p}_{r}$ noktalarından geçen $\mathrm{d}_{\text {ös }}$ denklemi ait olduğu ÖS için öğrenme stili doğrusu olarak adlandırılır. Bu doğrunun denkleminin eğimi $(m)$ maxÖS modelinden göstermiş olduğu sapmayı belirtmektedir.

$$
\begin{aligned}
& d_{\ddot{O} S} \Rightarrow \frac{y_{2}-y_{1}}{x_{2}-x_{1}}=\frac{y-y_{2}}{x-x_{2}} \Rightarrow \frac{p_{r}-p_{l}}{1.00}=\frac{y-p_{r}}{x-.50} \\
& f(x)=\left[\left(p_{r}-p_{l}\right) \times(x-.50)\right]+p_{r} \\
& \tan \alpha=m=\frac{y_{2}-y_{1}}{x_{2}-x_{1}} \rightarrow m=\frac{p_{r}-p_{l}}{1.00}=p_{r}-p_{l} \\
& \tan \alpha=p_{r}-p_{l} \rightarrow \alpha=\arctan \left(p_{r}-p_{l}\right)
\end{aligned}
$$


Tablo 1. (devam ediyor)

Dengedeki bir ÖS modeli maxÖS olarak kabul edilir. maxÖS modelindeki $p_{l}$ ve $p_{r}$ eşittir, bu noktalardan geçen $\mathrm{d}_{\mathrm{O} s}=.50$ olarak $x$ ekseni ile arasında kalan bölgeyi Sös olarak tanımlar.

$$
\begin{aligned}
& \mathrm{S}_{\ddot{\mathrm{OS}} \mathrm{S}}=\mathrm{S}_{\mathrm{LH}}+\mathrm{S}_{\mathrm{RH}} \quad S_{L H}=\int_{-.50}^{0} f(x) d x ; S_{R H}=\int_{0}^{+.50} f(x) d x \text { drr. Buna göre } \\
& S_{\ddot{O S}}=\int_{-.50}^{+.50} f(x) d x
\end{aligned}
$$

maxÖS de alt boyut için

$$
\begin{gathered}
S_{\ddot{O} S}=\int_{-.50}^{+.50} f(x) d x=\left..50(x)\right|_{-.50} ^{+.50}=-(.50 \times-.50)+(.50 \times .50)=50 \times 10^{-2} S \\
\max \ddot{O} S=\max _{L H}+\max _{R H}=4(\text { altboyut }) *\left(50 \times 10^{-2}\right)=2 S
\end{gathered}
$$

Dengesiz dağılım gösteren ÖS modellerinde maxÖS modeline göre $\mathrm{S}_{\text {ös'lerde değişmeler }}$ meydana gelecektir. Bu değişim oranı $\mathrm{DOS}_{\text {ös }}$ olarak belirtilir.

$$
\Delta S_{\ddot{O S}}=\left|S_{\ddot{O S}}-\max S \ddot{O} S\right| ; D O S_{\ddot{O} S}=\frac{\left|\Delta S_{\ddot{O} S}\right|}{\max _{\ddot{O} S}} \times 100
$$

$f_{L}$ ve $f_{R}$ skaler çarpımı sonucunda ÖS gücüne ulaşılır ve $G_{O ̈ s}$ olarak ifade edilir. Başka bir ifade ile $G_{O ̈ S}$ yarıkürelerdeki ÖS' nin ortaklaşa oluşturdukları ÖS gücü olarak değerlendirilebilir. $G_{\ddot{O} S}=\left|f_{L H}\right| \times\left|f_{R H}\right|$

ÖS modelindeki $\mathrm{G}_{\text {ös }}$ de meydana gelen kayıp oranı (KOG̈̈̈), maxÖS uzaklaştıkça ÖS'nin gücünün ne oranda düştüğünü açıklamaktadır. maxÖS modelindeki $\mathrm{G}_{O ̈ S}$

$$
\begin{aligned}
& \max \ddot{O} S G_{\ddot{O} S}=\left|-50 \times 10^{-2}\right| \times\left|50 \times 10^{-2}\right|=25 \times 10^{-2} G \\
& K O G_{\ddot{O} S}=\frac{\left|G_{\ddot{O} S}-\max \ddot{O} S G_{\ddot{O} S}\right|}{\max \ddot{O} S G_{\ddot{O} S}} \times 100
\end{aligned}
$$

\section{Araştırmanın Önemi ve Amacı}

Öğrenme stilleri ve öğrenme stilleri ile farklı değişkenler arasındaki ilişkisel çalışmalarda birçok farklı yöntem ve modeller uygulanmaktadır. Kolb ve Kolb (2005), Felder ve Soloman (1994) ya da Dunn ve Dunn (1999) gibi geçmişte yapılan araştırmaların yanı sıra son dönemde yapılan ve disiplinler arası yaklaşımları içeren araştırmalar da dikkat çekicidir. Bu araştırmalara, veri madenciliği türlerinden kaba kümeler veri analizleri ile öğrenme stilleri ve çoklu zeka arasındaki ilişkisel araştırmalar (Narlı, Özgen ve Alkan, 2011), Rana ve Lal (2014)'ın kaba kümeler teorisi bağlamında öğrenme stillerini incelemesi ve yine Narlı, Aksoy ve Ercire 
(2014)'nin matematik öğretmen adaylarının öğrenme stilleri ve arasındaki ilişkileri inceleyen çalışmaları örnek olarak verilebilir.

Yukarıda söz edilen güncel çalışmalarla birlikte, matematiksel bir algoritmanın kullanılması ile öğrenme stillerinin modellenmesinin, öğrenme stilleri ile beyin yarıküreleri arasındaki ilişkinin somut olarak yorumlanmasına katkı sağlayacağı düşünülmektedir. $\mathrm{Bu}$ bağlamda, okul öncesi öğretmen adaylarının öğrenme stillerinin matematiksel olarak modellenmesi, araştırmanın amacı olarak belirlenmiştir.

\section{Yöntem}

Araştırmanın yöntem bölümünde; desen, çalışma grubu, veri toplama aracı ile bu araca ilişkin geçerlilik-güvenirlik sonuçlarına ve verilerin analizine yer verilmiştir.

\section{Desen}

Nicel araştırma tekniği ve tarama yöntemi çalışmanın deseni olarak tercih edilmiștir. Karasar (2013) betimsel nitelikli tarama modelini en genel haliyle ilgilenilen bir durumu tanımlayarak (betimsel araştırma), var olan bu durumu var olduğu biçimde ve nesnel bir yaklaşımla ortaya koyma çabası (tarama modeli) olarak belirtmektedir.

\section{Çalıșma Grubu}

Araştırma grubu, ulaşılabilir ve amaçsal örnekleme yöntemi ile seçilmiştir (Büyüköztürk, 2007). Çalışma 2015-2016 öğretim yılında Ankara ilinde bulunan bir devlet üniversitesinin okul öncesi eğitimi anabilim dalı lisans öğrencileri ile yürütülmüsşür. Araştırmaya katılan 159 öğretmen adayının 36'sı bir, 42'si iki, 43'ü üç ve 38 'i de dördüncü sınıfa devam etmektedir.

\section{Veri Toplama Araçları}

Araştırmada Felder ve Soloman (1994)'ın geliştirdiği, Samancı ve Keskin (2007)'in Türkçeye uyarladığı ÖSE kullanılmıştır. Felder ve Soloman (1994) Öğrenme Stili Envanterinde dört alt boyuta (yansitıc1/aktif, ya/ak; sezgisel/algısal, se/al/; işitsel/görsel, iş/gö ve sıralı/bütünsel, sl/bü) yer vererek her öğrenme stili boyutunu 11 maddelik zıt kutuplu tercihlerle belirlemeye çalışmıştır. Ölçekteki alt boyutlarda yer alan maddeler tercihlere göre zıt kutuplu bir yapı alır. Örneğin, gö/iss alt boyutunda yer alan bir madde için ya gö tercihini içeren yanıt ya da iş tercihini içeren yanıt işaretlenir. Her alt boyuta ilişkin birer madde ve yanıtları örnek olarak verilmiştir.

$\mathrm{Ak} / Y a$ Alt boyutu için örnek bir madde:

Madde 1: Bir şeyi sonra daha iyi anlarım.

(a) yaptıktan (aktif) 
(b) detaylı düşündükten (yansıtıcı)

Al/Se Alt boyutu için örnek bir madde:

Madde 2: olarak görülmek isterim.

(a) gerçekçi (algısal)

(b) yenilikçi (sezgisel)

Gö/İş Alt boyutu için örnek bir madde:

Madde 3: Dün ne yaptığımı düşündüğümde, aklıma daha çok

(a) bir resim gelir (görsel)

(b) kelimeler gelir (işitsel)

S1/Bü Alt boyutu için örnek bir madde:

Madde 4: Genellikle kafamda belirsizlikler kalır.

(a) bir konuyla ilgili ayrıntıları anlarım ama bütünü hakkında (sıralı)

(b) bütünü anlarım ama detayları konusunda (bütünsel)

\section{ÖSE'nin Güvenirlik ve Geçerlilik Bilgileri}

ÖSE’nin önceden yapılan güvenirlik-geçerlilik çalışmalarında kullanılan ve her bir alt boyut için ayrı hesaplanan Cronbach alpha değerleri bulunmuştur. Cronbach alpha değerleri, $\mathrm{Ya} / \mathrm{Ak}$ alt boyutu için $.799, \mathrm{Se} / \mathrm{Al}$ alt boyutu için $.789, \dot{I}_{S} / \mathrm{Gö}$ alt boyutu için .865 ve $S l / B \ddot{u}$ alt boyutu için de .788 olarak hesaplanmıştır. Alt boyutlar için hesaplanan iç-tutarlılık katsayısının önceki çalışmalarda (Litzinger, Lee, Wise ve Felder, 2005; Livesay, Dee, Nauman ve Hites 2002; Samanc1 ve Keskin, 2007; Van Zwanenberg, Wilkinson and Anderson, 2000; Zywno, 2003) bulunan değerlere yakın ve bazılarından yüksek olması, envanter kullanılabilecek ölçüde güvenilir olduğunu göstermektedir.

\section{Verilerin Analizi}

Verilerin analizinde betimsel istatistikler ve modellemeye ulaşılması amacıyla matematiksel analizin parçası olan integral hesaplamaları kullanılmıştır. Bunun yanı sıra modelin teorik ve pratik uygulamalarının karşılaştırılması için $t$-Test uygulanmıştır. Elde edilen sonuçlara göre de öğrenme stili eğrilerine ve grafiklerine ulaşılarak analitik düzlemde çizilen doğruların ve grafiklerin alansal hesaplamaları yapılmışırır.

\section{Bulgular}

Bu bölümde sırasıyla öğretmen adaylarının öğrenme stillerine ilişkin bulgular ve bulgulardan elde edilen öğretmen adaylarının öğrenme stilleri modellemeleri sunulmuştur. 


\section{Aday Öğretmenlerin Öğrenme Stillerine İlişkin Bulgular}

ÖSE'deki ÖS frekanslarından elde edilen ÖS noktaları Tablo 2'de sunulmuştur.

Tablo 2.

ÖS Alt Boyutlarının ÖSE'deki Frekanslarına Göre ÖS Noktaları

\begin{tabular}{ccc}
$\begin{array}{c}\text { Alt } \\
\text { boyutl } \\
\text { ar }\end{array}$ & Sol yarıüre ÖS nokta değerleri & Sağ yarı̈üre ÖS nokta değerleri \\
\hline$y a / a k$ & $p_{y a}=\frac{f_{y a}}{f_{y a}+f_{a k}}=\frac{570}{570+1179}=.33$ & $p_{a k}=\frac{f_{a k}}{f_{y a}+f_{a k}}=\frac{11179}{771+1179}=.67$ \\
\hline se/al & $p_{s e}=\frac{f_{s e}}{f_{s e}+f_{a l}}=\frac{800}{800+949}=.46$ & $p_{a l}=\frac{f_{a l}}{f_{s e}+f_{a l}}=\frac{949}{800+949}=.54$ \\
\hline$i s / g \ddot{o}$ & $p_{i s ̧}=\frac{f_{i s}}{f_{i s}+f_{g o ̈}}=\frac{519}{519+1230}=.30$ & $p_{g o ̈}=\frac{f_{g \ddot{o}}}{f_{i s}+f_{g \ddot{o}}}=\frac{1230}{519+1230}=.70$ \\
\hline$s l / b \ddot{u}$ & $p_{s l}=\frac{f_{s l}}{f_{s l}+f_{b \ddot{u}}}=\frac{911}{911+838}=.52$ & $p_{b u ̈}=\frac{f_{b \ddot{u}}}{f_{s l}+f_{b \ddot{u}}}=\frac{838}{911+838}=.48$ \\
\hline
\end{tabular}

$\mathrm{Bu}$ sonuçlara göre en genel durumu ile öğretmen adaylarının aktif/algısal/görsel ve bütünsel öğrenme eğiliminde oldukları görülmektedir. Aday öğretmenlerin baskın öğrenme stilleri aktif (\% 67) ve görsel öğrenme (\% 70) olarak ölçülmüştür. Aktif ile yansıtıcı öğrenme stili arasında \% 34, görsel ile işitsel öğrenme stili arasında \% 40 oranda fark olduğu bulunmuştur. Diğer öğrenme stili alt boyutlarından sezgisel ile algısal ögrenme stili arasında $\% 8$ ve sıralı ile bütünsel öğrenme stili arasında da \% 4 gibi düşük bir oran farkı olduğu görülmektedir. Elde edilen sonuçların, Ültanır, Ültanır ve Temel (2012)'in farklı bölümlerde eğitim gören lisans öğrencileri ile yaptıkları ve deneklerde algısal, görsel ile sıralı öğrenme eğilimlerinin öne çıktığını rapor ettikleri çalışmayla uyumludur. Benzer şekilde mühendislik öğrencileri ile yapılan ve görsel öğrenme stilinin diğer öğrenme stillerine göre daha baskın çıktığı belirtilen araştırmalarla da paralellik göstermektedir (Alumran, 2008; Constant, 1997; Litzinger ve diğerleri, 2005; Zywno, 2003).

Elde edilen ÖS noktalarından geçen ÖS doğrularının denklemleri Tablo 3 'te sunulmuştur. 
Tablo 3.

ÖS Doğru Denklemleri

ÖS doğru denklemleri ve sapma açıları

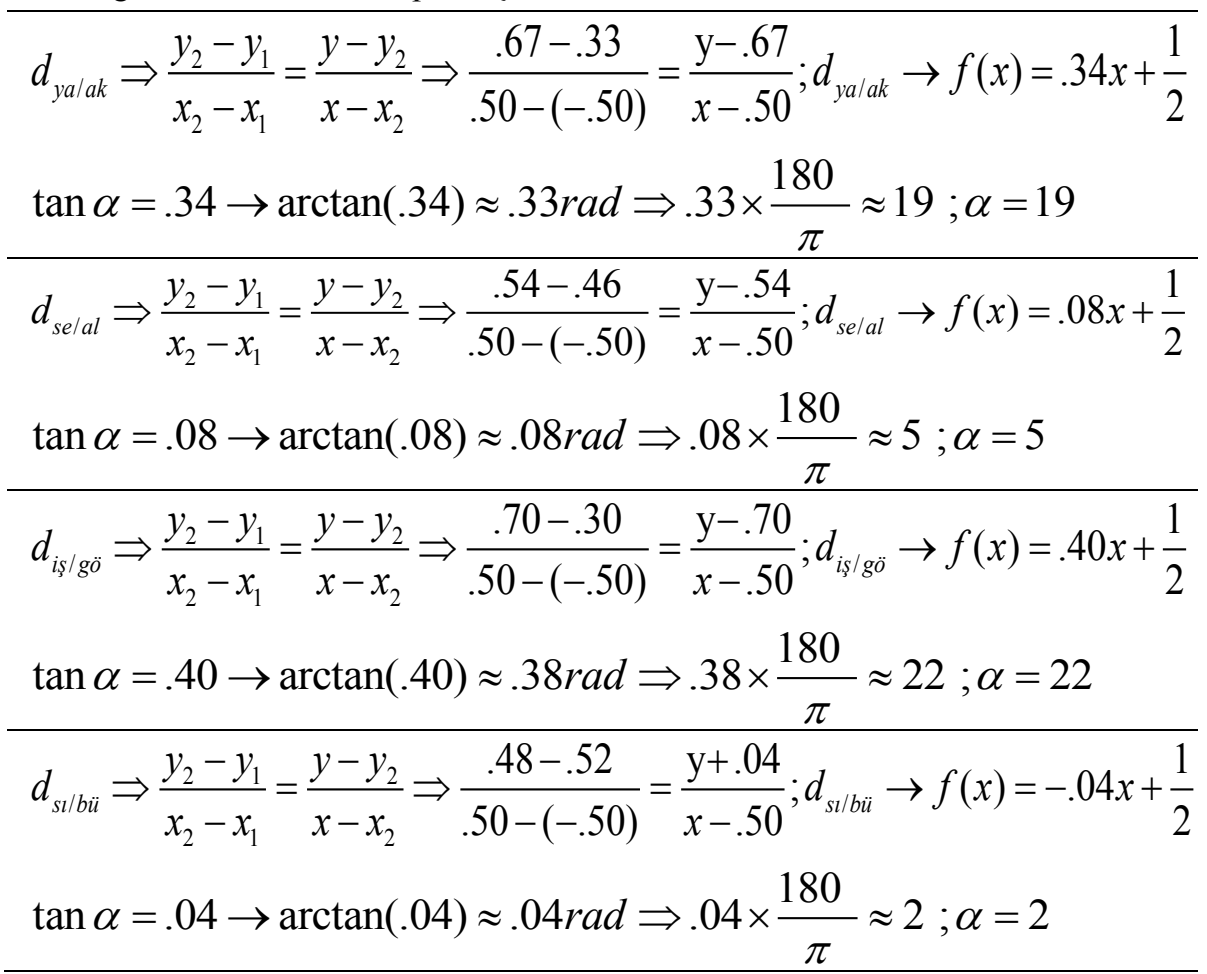

Tablo 3' te elde edilen ÖS doğru denklemlerinin oluşturdukları fonksiyonların analitik düzlemde gösterimi Şekil 2'de sunulmuştur.

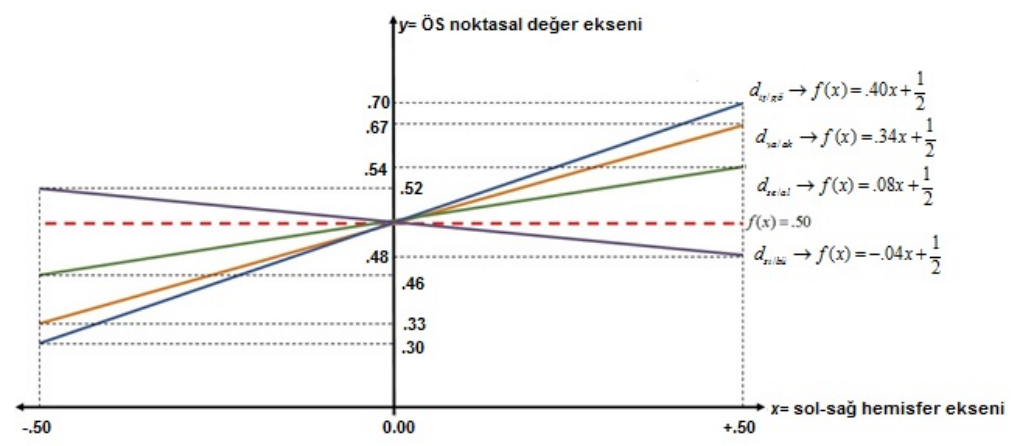

Şekil 2. ÖS doğrularının analitik düzlemde gösterimi 
Şekil 2'de görüldüğü gibi ÖS alt boyut noktaları arasından geçen ÖS doğruları, $x$ ekseni ile arasında kalan bölge için ÖS alanlarını tanımlamaktadır. Buna göre $y$ eksenine göre saat yönünün tersinde kalan bölgeler LH'de oluşan, saat yönünde kalan bölgeler ise RH'de oluşan ÖS alanları olarak değerlendirilmektedir. Bunun yanı sıra ÖS doğrularında eğim artıkça, maxÖS modeli için kabul edilen normalden $[\mathrm{f}(x)=.50]$ sapmalar da artmakta ve sapmanın olduğu yarıküredeki ÖS alanı genişlerken diğer yarıküredeki ÖS alanı daralmaktadır. ÖS dört alt boyutundan, ya/ak doğrusunun yarıkürelerde belirttiği alan Şekil 3 'te örnek olarak sunulmuştur.

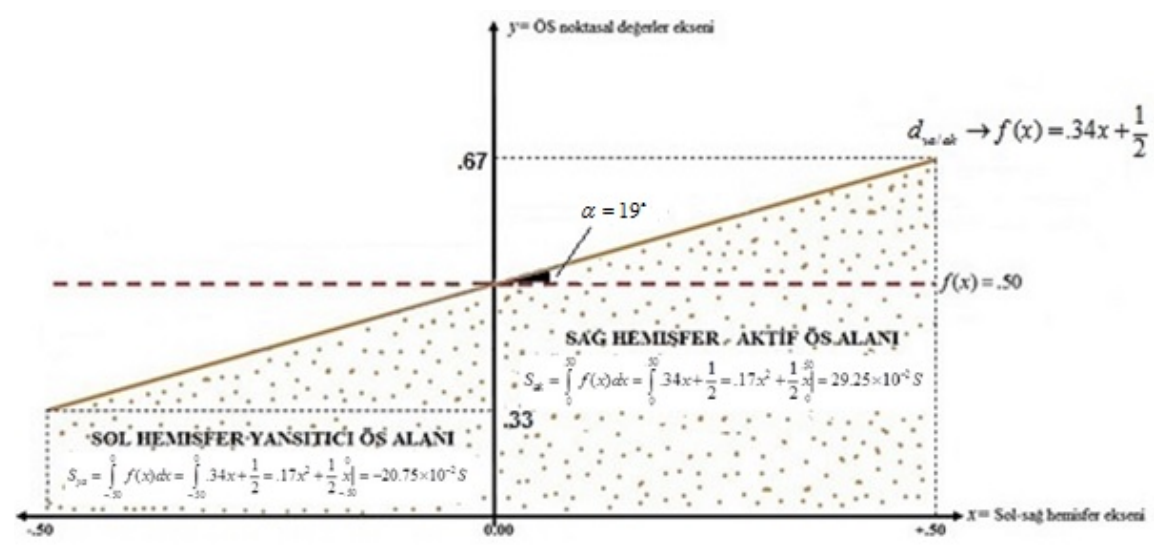

Şekil 3. Ya/Ak ÖS alt boyutunun yarıkürelerde kapladığı alanın analitik gösterimi

Şekil 3 'te görüldüğü gibi ya/ak ÖS alt boyutuna ilişkin ÖS alanı, sol yarıürede $20.75 \times 10^{-2} \mathrm{~S}$ iken sağ yarıkürede $29.25 \times 10^{-2} \mathrm{~S}$ olarak hesaplanmıştır. Elde edilen sonuçlara göre ya/ak alt boyutunda aday öğretmenlerin aktif öğrenmeyi daha yoğun kullandıkları söylenebilir. Bunun yanı sıra ya/ak ÖS doğrusunun yapmış olduğu sapma miktarının $\alpha=19^{\circ}$ olduğu görülmektedir. Sapma miktarının artması $y$ eksenine doğru yaklaşmaya ve buna bağlı olarak da bu örnek için sol yarküre alanında azalmaya neden olmaktadır. Öğretmen adaylarının ÖS dağılımlarının, maxÖS modeline göre istatistiksel olarak anlamlı bir farklılaşma gösterip göstermediğini, başka bir ifade ile ulaşılan ÖS modelinin maxÖS sınırlarından anlamlı şekilde uzaklaşıp uzaklaşmadığının anlaşılması için yapılan bağımsız gruplar t-testi sonuçları Tablo 4'te sunulmuştur (maxÖS için max uç değerler her alt boyuttaki 11 soru için $[(1+2) / 2] * 11=16.50$ ’ dir).

Tablo 4'te görüldüğü gibi ya/ak, se/al ile işs/gö yanıt dağılımlarının, maksimum alanları veren yanıtların dağılımından istatistiksel olarak anlamlı şekilde farklılık gösterdiği, öte yandan $s ı / b \ddot{u}$ alt boyut yanıtlarında ise bu farkın görülmediği anlaşılmaktadır. 
Tablo 4.

MaxÖS modeline göre öğretmen adaylarının öğrenme stillerine ilişskin bağımsız gruplar t-testi sonuçlart

\begin{tabular}{|c|c|c|c|c|c|c|}
\hline Alt Boyutlar & Grup & $\bar{X}$ & SS & sd & $\mathbf{t}$ & p \\
\hline \multirow{2}{*}{$\mathbf{Y a} / \mathbf{A k}$} & Uygulama & 14.59 & \multirow[t]{2}{*}{2.90} & \multirow{2}{*}{316} & \multirow{2}{*}{-8.315} & \multirow{2}{*}{.000} \\
\hline & Teorik & 16.50 & & & & \\
\hline \multirow{2}{*}{ Se/Al } & Uygulama & 16.97 & \multirow[t]{2}{*}{3.02} & \multirow{2}{*}{316} & \multirow{2}{*}{1.954} & \multirow{2}{*}{.000} \\
\hline & Teorik & 16.50 & & & & \\
\hline \multirow{2}{*}{ İş/Gö } & Uygulama & 14.27 & \multirow[t]{2}{*}{3.23} & \multirow{2}{*}{316} & \multirow{2}{*}{-8.717} & \multirow{2}{*}{.000} \\
\hline & Teorik & 16.50 & & & & \\
\hline \multirow{2}{*}{ Si/Bü } & Uygulama & 16.73 & \multirow[t]{2}{*}{3.07} & \multirow{2}{*}{316} & \multirow{2}{*}{.942} & \multirow{2}{*}{.347} \\
\hline & Teorik & 16.50 & & & & \\
\hline
\end{tabular}

Tablo 4'teki sonuca göre, elde edilen modelin maxÖS modelinden genel anlamda uzaklaşarak ÖS alanlarında değişim ve buna bağlı olarak gelişecek ÖS gücünde de kaybın olacağı şeklinde yorumlanabilir. ÖS doğru denklemleri incelendiğinde, maxÖS modelinden istatistiksel olarak anlamlı şekilde farklılaşmayan $s ı / b \ddot{u}$ ÖS fonksiyonundaki sapma açısının $2^{\circ}$ ve bu açıya en yakın ama maxÖS modelinden istatistiksel olarak anlamlı şekilde farklılık gösteren se/al doğrusundaki sapma açısının ise $5^{\circ}$ olduğu görülmektedir. Buna göre, ÖS modellerinin maxÖS modelinden istatistiksel olarak anlamlı şekilde farklılaşmasında, ÖS doğru denklemlerinin sapma açıları için kritik değer aralığının $2^{\circ}$ ile $5^{\circ}$ arasında olduğu söylenebilir.

ÖS alt boyutlarında oluşan alanların ait oldukları yarıkürelerde kapladıkları alanlar aşağıda hesaplanmıştır.

\section{LH'deki ÖS alt boyut alanları}

$$
\begin{aligned}
& S_{y a}=\int_{-.50}^{0} f(x) d x=\int_{-.50}^{0} .34 x+\frac{1}{2}=.17 x^{2}+\frac{1}{2} x_{-.50}^{0}=-20.75 \times 10^{-2} S \\
& S_{s e}=\int_{-.50}^{0} f(x) d x=\int_{-.50}^{0} .08 x+\frac{1}{2}=.04 x^{2}+\frac{1}{2}{ }_{-.50}^{0} \mid=-24.00 \times 10^{-2} S \\
& S_{i s}=\int_{-.50}^{0} f(x) d x=\int_{-.50}^{0} .40 x+\frac{1}{2}=.20 x^{2}+\left.\frac{1}{2} \frac{0}{x}\right|_{-.50}=-20.00 \times 10^{-2} S \\
& S_{s l}=\int_{-.50}^{0} f(x) d x=\int_{-.50}^{0}-.04 x+\frac{1}{2}=-.02 x^{2}+\left.\frac{1}{2} \frac{0}{2}\right|_{-.50} ^{0}=-24.50 \times 10^{-2} S
\end{aligned}
$$




\section{RH'deki ÖS alt boyut alanları}

$$
\begin{aligned}
& S_{a k}=\int_{0}^{.50} f(x) d x=\int_{0}^{.50} .34 x+\frac{1}{2}=.17 x^{2}+\frac{1}{2}{ }_{0}^{.50} \mid=29.25 \times 10^{-2} S \\
& S_{a l}=\int_{0}^{.50} f(x) d x=\int_{0}^{.50} .08 x+\frac{1}{2}=.04 x^{2}+\frac{1}{2} x_{0}^{.50} \mid=26.00 \times 10^{-2} S \\
& S_{g \ddot{o}}=\int_{0}^{.50} f(x) d x=\int_{0}^{.50} .40 x+\frac{1}{2}=.20 x^{2}+\frac{1}{2} x_{0}^{.50} \mid=30.00 \times 10^{-2} S \\
& S_{b u}=\int_{0}^{.50} f(x) d x=\int_{0}^{.50}-.04 x+\frac{1}{2}=-.02 x^{2}+\frac{1}{2} \underset{0}{x} \mid=25.50 \times 10^{-2} S
\end{aligned}
$$

ÖS alt boyutlarının oluşturdukları ÖS alanlarının RH'de yoğunlaştığı görülmektedir. LH'deki en büyük sapmanın ise yansitıcı ve işitsel öğrenme alt boyutlarında olduğu söylenebilir. Öte yandan bu alanlardaki daralma aynı oranda RH'deki genişlemeyi açıklamaktadır. Bunun yanı sıra bu iki alt boyutun her iki yarıkürede oluşturdukları ÖS alanları arasındaki nicel farkın diğer iki alt boyuta oranla daha fazla olduğu görülmektedir. Hesaplanan ÖS alt boyut alanlarının maxÖS modeli alt boyut alanlarına göre değişimi ise;

\section{ÖS Gücündeki Kayıp Miktarı}

ÖS

$$
\begin{aligned}
& D O S_{y a / a k}=\frac{\left|\Delta S_{\ddot{O} S}\right|}{\max S_{\ddot{O} S}} \times 100=\frac{\left|8.50 \times 10^{-2}\right|}{25 \times 10^{-2}} \times 100=\% 34.00 \quad \alpha=19 \\
& D O S_{\text {se } / a l}=\frac{\left|\Delta S_{\ddot{O S}}\right|}{\max S_{\ddot{O S}}} \times 100=\frac{\left|2.00 \times 10^{-2}\right|}{25 \times 10^{-2}} \times 100=\% 8.00 \quad \alpha=5 \\
& \operatorname{DOS}_{i \varsigma / g \ddot{o}}=\frac{\left|\Delta S_{\ddot{O} S}\right|}{\max _{\ddot{O} S}} \times 100=\frac{\left|10.00 \times 10^{-2}\right|}{25 \times 10^{-2}} \times 100=\% 40.00 \quad \alpha=22 \\
& D O S_{s l b u ̈}=\frac{\left|\Delta S_{\ddot{O S}}\right|}{\max S_{\ddot{O} S}} \times 100=\frac{\left|1.00 \times 10^{-2}\right|}{25 \times 10^{-2}} \times 100=\% 4.00 \quad \alpha=2
\end{aligned}
$$

olarak bulunur. Bu sonuçlara göre, sapma açısı en büyük olan iş/gö ÖS doğrusunun alansal değişimi maxÖS modeline göre en büyük değeri almaktadır. En düşük alansal değişim ise en küçük sapma açısını gösteren $\left(\alpha=2^{\circ}\right) s ı / b \ddot{u}$ ÖS alt boyut 
alanında meydana gelmektedir. Modelin çıkarımlarından biri de ÖS doğrularının sapma miktarlarının ÖS alanlarındaki değişimi açıklamasıdır. ÖS doğrularındaki sapma açılarının tanjant değerleri, ÖS alanlarındaki kayba eşittir. Bu örnekte ya/ak alt boyutundaki sapma açısının değeri tan $19^{\circ} \approx 34$, alandaki kayıp ise \%34 dür. Öğretmen adaylarının ÖS modelinin, teorik olarak kabul edilen maxÖS modeline göre değişimi görsel olarak incelenmektedir. Modelin grafiği çizilirken ÖS frekans değerleri, grafikte yer alan alt boyut eksenleri üzerinde konumlandırılmaktadır. Örneklemin ÖS model grafiği Şekil 4'te sunulmuştur.

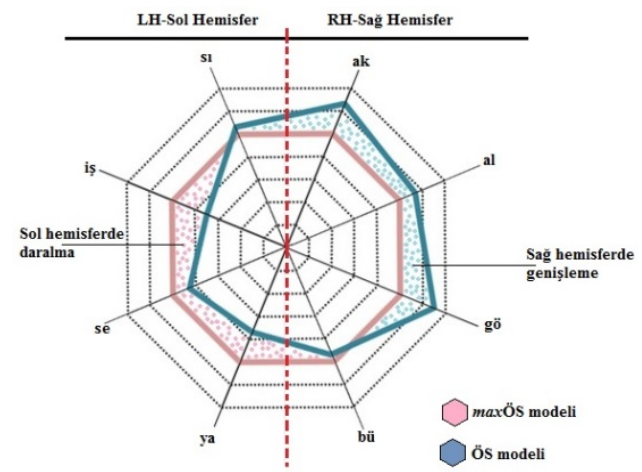

Şekil 4. Öğretmen adaylarının ÖS modeli grafiği

Şekil 4'teki ÖS modeline göre, örneklemi oluşturan okul öncesi aday öğretmenlerin sağ yarıüreyi sol yarıküreye oranla daha yoğun şekilde kullanmaktadırlar. Daha önce yapılan ÖS alt boyut alanlar hesabına göre yarıkürelerdeki toplam ÖS alanları:

$$
\begin{aligned}
& \sum S_{L H}=S_{y a}+S_{s e}+S_{i s}+S_{s l} \text { ve } \\
& \sum S_{R H}=S_{a k}+S_{a l}+S_{g \ddot{o}}+S_{b \ddot{u}} \text { esitliklerinden } \\
& \sum S_{L H}=20.75 \times 10^{-2} \mathrm{~S}+24.00 \times 10^{-2} \mathrm{~S}+20.00 \times 10^{-2} \mathrm{~S}+24.50 \times 10^{-2} \mathrm{~S}=0.89 \mathrm{~S} \\
& \sum S_{R H}=29.25 \times 10^{-2} \mathrm{~S}+26.00 \times 10^{-2} \mathrm{~S}+30.00 \times 10^{-2} \mathrm{~S}+25.50 \times 10^{-2} \mathrm{~S}=1.11 S
\end{aligned}
$$

olarak bulunur. $\mathrm{Bu}$ sonuçlara göre okul öncesi öğretmen adaylarının ÖS tercihlerinde \% 11 oranında (maxÖS modeline göre) maksimum ÖS yarıüre alanları 1S sağ yarıürenin kontrolünde olan ÖS tercihlerine doğru kayma yaptığ1, başka bir ifade ile sağ yarıkürenin \% 11 oranda daha yoğun kullanıldığı söylenebilir. 
Modelde yer alan her bir ÖS alt boyut alanlarından, ilgili alt boyuttaki $\mathrm{G}_{\text {ös }}$ değerine ulaşılır. ÖS alt boyutlarının ortak etkisinde gelişen $\mathrm{G}_{\text {ÖS }}$ değerlerinin alt boyutlara göre değerleri aşağıda sunulmuştur.

Ulaşılan Gös değerleri maxÖS modelindeki Gös değerleri ile karşılaştırıldığında, öğrenme stilindeki güç kaybının;

$$
\begin{aligned}
& K O G_{\ddot{O S}}=\frac{\left|G_{\ddot{O} S}-\max \ddot{O} S G_{\ddot{O S}}\right|}{\max \ddot{O} S G_{\ddot{O} S}} \times 100 \text { formülünden: } \\
& y a / a k \rightarrow K O G_{\ddot{O S}}=\frac{\left|25.00 \times 10^{-2}-22.11 \times 10^{-2}\right|}{25.00 \times 10^{-2}} \times 100=\% 11.56 \\
& \text { se } / \mathrm{al} \rightarrow K O G_{\ddot{O} S}=\frac{\left|25.00 \times 10^{-2}-24.84 \times 10^{-2}\right|}{25.00 \times 10^{-2}} \times 100=\% 0.64 \\
& i \text { is / } g \ddot{o} \rightarrow K O G_{\ddot{O S}}=\frac{\left|25.00 \times 10^{-2}-21.00 \times 10^{-2}\right|}{25.00 \times 10^{-2}} \times 100=\% 16.00 \\
& s l / b \ddot{u} \rightarrow K O G_{\ddot{O} S}=\frac{\left|24.96 \times 10^{-2}-25.00 \times 10^{-2}\right|}{25.00 \times 10^{-2}} \times 100=0.16
\end{aligned}
$$

olduğu görülmektedir. Zit kutuplu ÖS tercihlerinin uzaklaşması durumunda yarıkürelerdeki ÖS alanları değişmekte ve buna bağlı olarak da ÖS gücü maxÖS modeline oranla azalmaktadır. Örneklemi oluşturan grubun ÖS tercihleri uç değerlerde yoğunlaşmadığı için nispeten dengeli bir dağılım olduğu düşünülebilir fakat $y a / a k$ ve iş/gö alt boyutlarındaki öğrenme stili güç kaybı kayda değer veriler

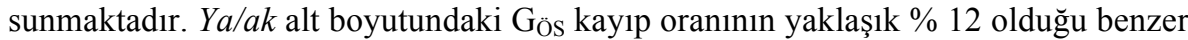

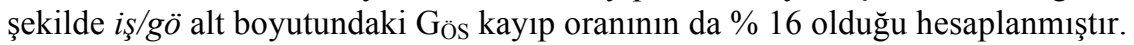

Modele ilişkin $\mathrm{G}_{\text {Ös }}$ değerleri grafiğe (spider graph) yansıtılmak istendiğinde, bu grafikte alt boyut eksen uzunlukları maxÖS modelinin sınır değerleri dikkate alınarak belirlenecektir. maxÖS modelin sınır değerleri $25.00 \times 10^{-2} \mathrm{br}$ olarak çizilecektir. Buna göre ya/ak eksenindeki Gös noktasal konumu $22.11 \times 10^{-2} \mathrm{br}$, se/al

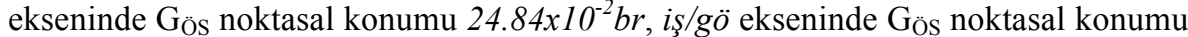
$21.00 \times 10^{-2} \mathrm{br}$ ve $s \imath / b \ddot{u}$ eksenindeki $\mathrm{G}_{\text {ös }}$ noktasal konumu $24.96 \times 10^{-2} \mathrm{br}$ olarak işaretlenecektir. Elde edilen $\mathrm{G}_{\mathrm{O} \text { s }}$ değerler grafiği Şekil 5 'te sunulmuştur. 


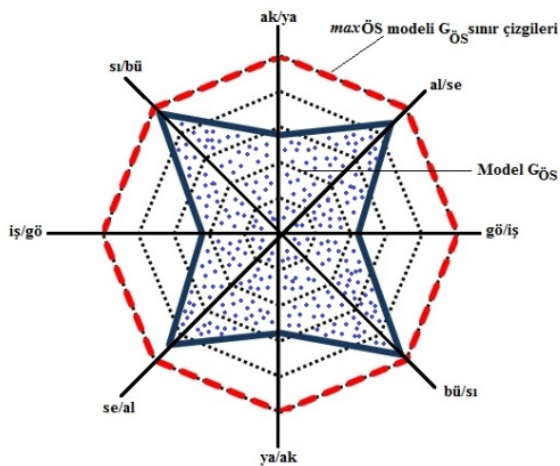

Şekil 5. ÖS modeli Gös grafiği

Şekil 5' te, iş/gö ve ya/ak ÖS alt boyut eksenlerinde konumlanan Gös'lerin merkeze doğru bükülme yaparak maxÖS modelinin $G_{\text {ös }}$ değerlerini belirten sınır noktalarından uzaklaştığı görülmektedir. Alt boyut eksenlerinde konumlanan

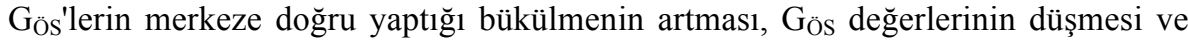
buna bağlı olarak da ÖS etkililiğinin azalması şeklinde yorumlanabilir. Öte yandan, $s / / b \ddot{u}$ alt boyutunun öğrenme stili güç kaybı olmamasından dolayı max sınır çizgisinde kaldığı görülmektedir.

Araştırma sonuçları genel olarak değerlendirildiğinde okul öncesi aday öğretmenlerinin aktif/algısal/görsel ve sıralı öğrenme stillerini daha yoğun kullandıkları söylenebilir. Araştırmanın sonuçlarını, Slaats, Lodewijks ve Van der Sanden (1999)'in sosyal bilimlerde eğitim gören öğrencilerle gerçekleştirdikleri araştırmada ulaştıkları benzer bulgular desteklemektedir. Öğretmen adaylarının öğrenme stillerinin aktif ve görsel öğrenme alt boyutlarında yoğunlaştığ 1 , bununla beraber sezgisel/algısal ve sıralı/bütünsel alt boyutlarında yer alan her iki öğrenme stilini de birbirine çok yakın kullandıkları görülmektedir. Bu noktada, araştırma grubunun hedef öğrenci kitlesi olan küçük yaş grubu çocuklarının da görsel, algısal, somut ve etkinliğe (kinestetik/dokunsal) dayalı öğrenmeye eğilimli oldukları bilinmektedir (Hawk ve Shah, 2007; Kolb ve Kolb, 2005). Çocukların aktif, algısal ve görsel öğrenme stillerini sergilemeleri, (Dunn ve diğ., 1995), bu alanda çalışacak olan öğretmen adaylarının öğrenme stilleri ile uyumlu olduğu sonucunu çıkarmaktadır. Öte yandan çocukların büyük bölümünün bütünsel öğrendiği rapor edilse de (Dunn ve diğ., 1995) son dönemde yapılan ve çocukların analitik düşünebildiklerine yönelik bulgular ortaya koyan çalışmalar da mevcuttur (Arnup, Murrihy, Roodenburg ve McLean, 2013; Koyré, 2000).

Yapılan araştırmada geliştirilen matematiksel modellemenin sonuçlarına göre, okul öncesi öğretmen adaylarının genel olarak sağ yarıküre kontrolündeki aktif, algısal ve görsel ile sol yarıküre kontrolündeki analitik (sıralı) öğrenme eğiliminde oldukları görülmektedir. Geliştirilen modelleme, etkili bir öğrenme için teorik olarak 
kabul edilen beynin tümü ile öğrenme (Healy, 2004) ve her iki yarıküreyi yakın şekilde kullanabilme (De Bello, 1990; Felder, 1996) becerilerinin, pratik olarak değerlendirilmesine olanak sağlamaktadır. Modelleme ve algoritmasının aday öğretmenlerin öğrenme stillerini analitik ve sistematik bir yaklaşımla ortaya koyduğu söylenebilir. Matematiksel modellemenin temel aldığı iki varsayımın, modelleme işlemlerinde tutarlı sonuçlar verdiği ve öğretmen adaylarının öğrenme stillerinde tek kutba doğru gösterdikleri eğilimlerin öğrenme stili güçlerini olumsuz şekilde etkilediği yapılan hesaplamalarla ortaya konulmuştur. Katılımcıların genel olarak sağ yarıkürenin kontrolündeki öğrenme stillerini kullanma oranlarının, sol yarıküredeki öğrenme stillerini kullanma oranlarına göre \% 11 oranda daha fazla olduğu görülmektedir. Buna bağlı olarak öğrenme stili alanlarının ortak etkisinde gelişen öğrenme stili gücü değerlerinin dengeli dağılım gösteren öğrenme stili gücüne oranla kayba uğramakta ve etkisinde azalma olduğu görülmektedir.

İlgili alanyazın incelendiğinde, bu araştırmada geliştirilen matematiksel algoritmaya dayalı modelin kesinlik ve sabitlik gibi önermeler içermesine rağmen Özek, Akpolat ve Orhan (2010) ile Uysal (2010) yaptıkları çalışmalarda bulanık mantık kullanarak öğrencilerin öğrenme stillerinin modellenebileceğini göstermişlerdir. Bununla beraber Narlı ve diğerlerinin (2011) yaptığı çalışmada, öğrencilerin öğrenme stillerinin belirlenmesinde, bulanık küme yaklaşımına ek olarak belirsizlik derecesi ve kesinlik derecesi gibi verilerden de yararlanılmasının yararlı olduğu tespiti kabul edilebilir. $\mathrm{Bu}$ bağlamda, geliştirilen modellemenin Felder ve Soloman (1994)'ın öğrenme stilleri için belirlediği öğrenme eğilimleri ile ilgili kavramsal çıkarımlar (öğrenme stili gücü, öğrenme stili alanları, öğrenme stillerinde meydana gelen sapmalar vb.) sunması geliştirilen modelin analitik ve kavramsal boyutta yeni tartışmaları gündeme getireceği düşünülmektedir.

\section{Tartışma, Sonuç ve Öneriler}

Bu çalışmada okul öncesi eğitim bölümüne devam eden 159 lisans öğrencisinin öğrenme stilleri, kuramsal temelleri De Bello (1990), Healy (2004) ve Felder (1996)'in görüşleri ile şekillenen ve algoritması araştırmacı tarafından geliştirilen matematiksel bir modelleme yöntemiyle incelenmeye çalışılmıştır. Araştırma sonuçlarına göre, aday öğretmenlerin sağ yarıküre kontrolündeki aktif ( $\left.\begin{array}{ll}\% & 67\end{array}\right)$, algısal (\% 57) ve görsel (\% 70) öğrenme stillerini ağırlıklı olarak tercih ettikleri bulunmuştur. Öte yandan sol yarıküre öğrenme stillerinden sıralı (analitik) öğrenme stilini (\% 52), bütünsel öğrenme stiline (\% 48) oranla biraz daha yoğun kullandıkları sonuçlarına ulaşılmıştır. Geliştirilen modelin, teorik olarak kabul edilen maxÖS modeline göre istatistiksel olarak anlamlı şekilde farklılaştığı görülmekte ve bu farklılık için ÖS alt boyut doğru denklemlerinin normale göre sapma açılarının kritik değer aralığının $5^{\circ}$ olduğu hesaplanmıştır. Bunun yanı sıra sapma açılarının öğrenme stili güçlerindeki kaybı da yordadığı saptanmıştır. Sapma açılarının tanjant değerleri, ulaşılan ÖS modellerinin maxÖS modeline göre kayıp oranlarını vermektedir. Yapılan uygulamada, öğretmen adaylarının sl/bü alt boyutu dışındaki tüm ÖS alt boyutlarında maxÖS modelinden uzaklaştığı ortaya konulmuştur. Bu sonuçlar, 
uygulama grubundaki se/al alt boyutunda gözlendiği gibi zit ÖS tercihlerinde dengeli dağılımların maxÖS modeli sınırları içinde kalındığını göstermesi açısından önemlidir. Sistem bütün olarak değerlendirildiğinde okul öncesi öğretmen adaylarının öğrenme stili tercihlerinin \% 11 oranda sağ yarıküreye doğru kaydığı hesaplanmıştır. Öğrenme stili alanlarının ortak etkisinde gelișen öğrenme stili güçlerinde ise en fazla kaybın tek yönlü öğrenmeye yatkın alt boyutlarda olduğu görülmüştür. Ya-ak alt boyutundaki öğrenme stili güç kaybı yaklaşık olarak \% 12 iken $i s ̧-g \ddot{o}$ alt boyutundaki öğrenme stili güç kaybı \% 16 olarak hesaplanmıştır.

Öğrenme stili alanlarındaki değişim ve öğrenme stili gücündeki kayıp değerlerin bilişsel gelişim üzerinde hangi oranlarda anlamlı farka neden olduğu yanıt aranması gereken yeni problemler ortaya koymaktadır. Geliştirilen model ile yaratıcılık, öğrenme becerileri ya da problem çözme becerileri gibi aday öğretmenlerin farklı alanlardaki gelişimlerinin incelendiği araştırmaların bu sorulara yanıt verebileceği düşünülmektedir. 


\section{Kaynakça}

Akpan, G. A., Essien, E. O., and Okure, O. S. (2013). Conceptual analysis and implications of students' individual differences to curriculum implementation in technical education. International Education Studies, 6(3), 156-161.

Arnup, J. L., Murrihy, C., Roodenburg, J., and McLean, L. A. (2013). Cognitive style and gender differences in children's mathematics achievement. Educational Studies, 39(3), 355-368. DOI: 10.1080/03055698.2013.767184

Alumran, J. I. A. (2008). Learning styles in relation to gender, field of study, and academic for Bahraini University students. Individual Differences Research, 6(4), 303-316.

Büyüköztürk, Ş. (2007). Veri analizi el kitabı (8. Baskı). Ankara: PegemA Yayıncilık.

Constant, K. P. (1997). Using multimedia techniques to address diverse learning styles in materials education. Journal of Materials Education, 19, 1-8.

De Bello, T. C. (1990). Comparison of eleven major learning styles models: Variables, appropriate populations, validity of instrumentation and the research behind them. Journal of Reading, Writing, and Learning Disabilities International, 6, 203-222.

Dilci, T., ve Babacan, T. (2011). Sınıf öğretmen adaylarının üstbilişsel okuma stratejileri ile çoklu zeka alanları arasındaki ilişkinin incelenmesi. Inönü Üniversitesi Eğitim Fakültesi Dergisi, 12(3), 47-64.

Dunn, R., Beaudry, J. S., and Klavas, A. (1989). Survey of research on learning styles. Education Leadership, 46(6), 50-57.

Dunn, R., and Dunn, K. (1999). The complete guide to the learning styles inservice system. Boston, MA, Allyn and Bacon.

Dunn, R., Griggs, S. A., Olson, J., and Beasley, M. (1995). A meta-analytic validation of the Dunn and Dunn model learning-style performances. The Journal of Educational Research, 88(6), 353-363.

Ekici, G. (2002). Gregorc öğrenme stili ölçeği. Eğitim ve Bilim, 27(123), 42-47.

Felder, R. M. (1996). Matters of style. ASEE Prism, 6(4), 23.

Felder, R. M., and Brent, R. (2005). Understanding students differences. Journal of Engineering Education, 57-72.

Felder, R. M., and Soloman, B. A. (1994). Index of learning styles. http://www.ncsu.edu/felder-public/ILSpage.html

Fleming, N. D. (2001). Teaching and learning styles: VARK strategies. New Zealand: Christchurch. 
Giedd, J. N., Snell, J. W., Lange, N., Rajapakse, J. C., Casey, B. C., Kozuch, P. L., Vaituzis, A. C, Vauss, Y. C., Hamburger, S. D., Kaysen, D., and Rapoport, J. L. (1996).Quantitative imagnetic resonance imaging of human brain development: Ages 4-18.Cerebral Cortex, 6, 551-560.

Gilbert, J. K. (2004). Models and modelling: Routes to more authentic science education. International Journal of Science and Mathematics Education, 2, 115-130.

Gregorc, A. F. (1979). Learning/teaching styles: Their nature and effects. NASSP Monograph, (October/November), 19-26.

Harrison, G. A., and Treagust, F. D. (2000). A Typology of science models. International Journal of Science Education, 22(9), 1011-1026.

Hawk, T. F., and Shah, A. J. (2007). Using learning styles instruments to enhance student learning. Decision Sciences Journal of Innovative Education, 5(1),1-19, Retrieved from. http://onlinelibrary.wiley.com/doi/10.1111/j.15404609.2007.00125.x/pdf

Healy, J. M. (2004). Your child's growing mind: Brain development and learning from birth to adolescence. New York: Broadway Books.

Herrmann, N. (1990). The creative brain. Lake Lure, North Carolina.

Iaccino, J. F. (2014). Left brain-right brain differences: Inquiries, evidence, and new approaches. New York: Pschology Press.

Karasar, N. (2013). Bilimsel araştırma yöntemi (25. Bask1). Ankara: Nobel Yayın Dağıtım.

Keefe, J. W. (1979). Learning Style: An Overview. In J. W. Keefe (Ed.), Student learning styles: Diagnosing and prescribing programs, Reston, Va: National Association of Secondary School Principals.

Kolb, D. A. (1984). Experiential learning: Experience as the source of learning and development. Englewood Cliffs, NJ: Prentice Hall.

Kolb, A. Y., and Kolb, D. A. (2005). Learning styles and learning spaces: Enhancing experiential learning in higher education. Academy of Management Learning and Education, 4(2), 193-212.

Koyré, A. (2000). Bilim tarihi yazıları I. Ankara: Tübitak Popüler Bilim Kitapları.

Lebel, C., and Beaulieu, C. (2011). Longitudinal development of human brain wiring continues from childhood into adulthood. The Journal of Neuroscience,31(30), 10937-10947.

Litzinger, T. A., Lee, S. H., Wise, J. C., and Felder, R. M. (2005). A study of the reliability and validity of the Felder-Soloman Index of Learning Styles. In American SocietyforEngineering Education Annual Conference and 


\section{Exposition.}

Retrieved

from

http://www4.ncsu.edu/unity/lockers/users/f/felder/public/ILSdir/Litzinger_Vali dation_Study.pdf

Livesay, G. A., Dee, K. C., Nauman, E. A., and Hites, L. S. (2002). Engineering student learning styles: A statistical analysis using Felder's index of learning styles. In Annual Conference of the American Society for Engineering Education, Montreal, Quebec.

Narlı, S., Aksoy, E., ve Ercire, Y. E. (2014). Veri madenciliği ile ilköğretim matematik öğretmen adaylarının öğrenme stillerinin ve aralarındaki ilişkilerin incelenmesi. International Journal of Educational Studies in Mathematics, 1(1), 37-57.

Narli, S., Ozgen, K., and Alkan, H. (2011). In the context of multiple intelligences theory, intelligent data analysis of learning styles was based on rough set theory. Learning andIndividual Differences, 21, 613- 618.

Özek, M. B., Akpolat, Z. H., and Orhan, A. (2010). Web tabanlı akıllı öğretim sistemlerinde tip-2 bulanık mantık kullanarak öğrenci öğrenme stili modelleme. Fırat Üniversitesi Mühendislik Bilimleri Dergisi, 22(1), 37-44.

Pehlivan, K. B. (2010). Öğretmen adaylarının öğrenme stilleri ve öğretmenlik mesleğineyönelik tutumları üzerine bir çalışma. İlköğretim Online, 9(2),749763.

Rana, H., and Lal, M. (2014). Rough set theory based reasoning of learning style in e-learning. International Journal of e-Education, e-Business, e-Management and e-Learning, 4(6), 423-434.

Reiss, A. L., Abrams, M. T., Singer, H. S., Ross, J. L., and Denckla, M. B. (1996). Brain development, gender and IQ in children A volumetric imaging study. Brain, 119, 1763-1774.

Samanc1, N. K. ve Keskin, M., Ö. (2007). Felder ve Soloman öğrenme stili indeksi: Türkçeye uyarlanması ve geçerlik-güvenirlik çalışması. Ahi Evran Üniversitesi Kırşehir Eğitim Fakültesi Dergisi, 8(2),37-54.

Sharp, S. E. (1899). Individual psychology: A study in psychological method. The American Journal of Psychology, 10(3), 329-391.

Slaats, A., Lodewijks, H. G. C., and Van der Sanden, J. M. M (1999). Learning styles in secondary vocational education: Disciplinary differences. Learning and Instruction, 9(5), 475-492.

Uysal, M. P. (2010). Öğrenme stillerinin bulanık mantıkla modellenmesi. 4th International Computer and Instructional Technologies Symposium, Selçuk University, Konya, Turkey, 1040-1045. 
Ültanır, E., Ültanır, Y. G., and Temel, G. Ö. (2012). The examination of university students' learning styles by means of Felder-Silverman Index. Education and Science, 37(163), 29-42.

Van Zwanenberg, N., Wilkinson, L.J., and Anderson, A., (2000). Felder and Silverman's index of learning styles and honey and mumford's learning styles questionnaire: How do they compare and do they predict academic performance? Educational Psychology, 20(3), 365-380.

Zhang, R. (2011). Cerebral hemispheres and learning: a study of the correlation between brain dominations and learning styles. International Journal of Scientific and Engineering Research, 2(12),1-6.

Zywno, M. S. (2003). A contribution of validation of score meaning for FelderSoloman's index of learning styles. In Annual Conference of the American Society Engineering Education, Washington, DC. 


\title{
Modeling of Pre-service Pre-School Teachers' Learning Styles based on Mathematical Algorithm
}

\begin{tabular}{lccc}
\hline ARTICLE TYPE & Received Date & Accepted Date & Online First Date \\
Research Article & 11.16 .2017 & 03.14 .2018 & 03.15 .2018 \\
\hline \multicolumn{4}{c}{ Gökhan Günes iD ${ }^{1}$} \\
\multicolumn{3}{c}{ Hakkari University }
\end{tabular}

\begin{abstract}
The aim of the study is to model the learning styles of pre-service preschool teachers by using a mathematical algorithm method. The research was conducted with 159 pre-service preschool teachers from a public university in Ankara in 2015-2016 academic year. The Index of Learning Styles (LSI) developed by Felder and Soloman (1994) was used as the data collection tool in the research. According to the results of the research, pre-service teachers were found to prefer the active, sensing and visual learning styles under the control of the right hemisphere more intensively, they were found to use the sequential (analytic) learning style under the control of the left hemisphere more intensively compared to the global learning style. In addition, as a result of the model developed, the powers of learning style with a greater deviation were calculated to have loss by $12 \%$ at reflective (re) / active (ac) and by $16 \%$ verbal (ve) / visual (vi) sub dimensions.
\end{abstract}

Keywords: Learning styles, mathematical model, pre-service early childhood teachers

\footnotetext{
${ }^{1}$ Corresponding Author: Asisst Prof., Faculty of Education, Division of Elementary Education, Early Childhood Education Department, E-mail: gokhangunes@hakkari.edu.tr, https://orcid.org/0000-00028923-3315
} 


\section{Summary}

The studies on psychology studies seem to have embodied individual differences towards the end of the 19th century (Sharp, 1899). Individual differences can be defined as unique differences perceived in behavior or physical appearance in each person, different from other people (Akpan, Essien and Okure, 2013). Learning is an individual process in the personal context. This process can be explained by the learning styles in which the learning tendencies or preferences of the individuals show different characteristics.

It is understood that the strong relationships between brain hemispheres and learning styles and also found that individuals who use the left-brain hemispheres intensively are better learners in visual and auditory environments, and those who use the right hemisphere learn better in visual learning environments (Zhang, 2011). It is emphasized that functions in the left hemisphere, such as logical and sequential thinking, linguistic knowledge, word and mathematical equations, and in the right hemisphere, the functions of sensing the whole, global, imaginary thinking and environments / shapes and performing strongly in the left hemisphere are performed weakly in the right hemisphere (Iaccino, 2014). Herrmann (1990) describes the brain with a four-tiered holistic model, with the left upper and lower quadrants and the right upper and lower quadrants. The left upper quartile in the model is responsible for rational, mathematical, analytical processing and grammar, and left lower quartile details, methodical thinking and motor skills. On the other hand, the right upper quartile is responsible for the ability to comprehend kinesthetic, painting, poetry and whole, while the right lower quartile is responsible for the skills such as music, communication, coding and using the native language. Purpose and Significance

\section{The Significance and Objective of the Research}

The model developed in the research is based on two basic assumptions. The first assumption is the function of the learning styles on left and right hemispheres of brain and the second assumption is learning style fields and the power of learning style that occurs in the common influences of the learning style fields.

Modeling of learning styles with using a mathematical algorithm is thought to contribute to the concrete interpretation of the relationship between learning styles and brain hemispheres. In this context, the purpose of the study is to determine the mathematical modeling of learning styles of pre-service preschool teacher.

\section{Method}

The sample of the study consists of 159 undergraduate students of the department of pre-school teaching in a state university in Ankara in the 2015-2016 academic year. The Index of Learning Styles (LSI) developed by Felder and Soloman (1994) was used as the data collection tool in the research. Each subdimension of LSI Cronbach alpha values were calculated between 0.788 and 0.865 . 


\section{Results}

According to the results of the research, it has been found that pre-service teacher have preferences towards active/perceptive/visual and global learning. The dominant learning styles of the preservice teachers were calculated as active $(67 \%)$ and visual learning (70\%). It was found that there was a difference of $40 \%$ between the active and the reflective learning style and $40 \%$ between the visual and verbal learning style. Of the other learning style sub-dimensions, there was a low ratio of difference at $4 \%$ between the sensing and sensing learning styles, and $8 \%$ difference between the sequential and global learning styles. The results obtained are in line with the study of Ültanır, Ültanır and Temel (2012) conducted with undergraduate students at different departments and in which they reported that sensing, visual and sequential learning tendencies prevail in the subjects.

According to the distribution of the responses constituting the theoretically accepted max LS model and the independent groups t-test between the LSI responses obtained in practice, it is understood that the distributions of the responses for the whole model and reflective/active, sensing/sensing and verbal/visual sub-dimensions showed a statistically significant difference than the distributions of the responses giving the maximum areas, on the other hand, this difference has not been seen in sequential/global sub-dimension responses.

Considering the results of the research in general, it can be stated that preservice pre-school teachers use active/perceptive/visual and sequential learning styles more intensely. Similar findings reached in the study conducted by Slaats, Lodewijks and Van der Sanden (1999) on students studying in social sciences support the results of the present research. It is seen that the learning styles of the pre-service teachers concentrate on the active and visual learning sub-dimensions, and they use both learning styles in the perceptive/intuitive and global/sequential sub-dimensions at very close rates.

\section{Discussion and Conclusions}

According to the results of the research, it was found that pre-service teachers prefer active (67\%), sensing (57\%) and visual (70\%) learning styles under the control of the right hemisphere intensively. On the other hand, the results showed that pre-service teachers used the sequential learning style $(52 \%)$ of the left hemisphere learning styles more intensively than the global learning style (48\%). The developed model was seen to be statistically different in a significant way than the theoretically accepted maxLS model and the critical value range of the deviation angles of the LS sub-dimension linear equations for this difference was calculated to be $5^{\circ}$. Considering the whole system as a whole, the learning style preferences of preservice pre-school teacher were calculated to shift towards the right hemisphere at the rate of $11 \%$. The greatest loss in the power of learning style developing under the common influence of the learning style areas was found to be at the subdimensions prone to one-way learning. While the learning style power loss in the 
reflective-active sub-dimension was approximately $12 \%$, the learning style power loss in the verbal-visual sub-dimension was calculated as $16 \%$.

The changes in learning-style domains and new learning styles reveal new problems that need to be addressed in what proportion of the missing values on the cognitive development cause a meaningful difference. It is believed that the developed model can respond to these questions through research that examines the development of pre-service teachers' in different areas such as creativity, learning skills or problem-solving skills. 